\title{
A PRELIMINARY REPORT OF PERSONALITY TRAITS ESSENTIAL TO THE SUCCESS OF THE PRACTISING DENTIST ${ }^{1}$
}

ROBERT K. BROWN, M.S., D.D.S.

School of Dentistry, University of Michigan, Ann Arbor, Mich.

Success in dental practice is the ultimate goal of every student or practitioner of dentistry. A study that would aid in reaching this objective would seem to be worth while. The fact that individuals differ makes the definition of success a varying statement, for each individual has a mental conception of success which is different in many respects from the conceptions of others. This situation will always exist and will cause variables that in a study of this kind can be considered only to a limited extent. The dental teacher's aim is to develop successful dentists, and his success should be determined to a large extent by this criterion, rather than by the number of his students who pass the dental licensing board. Teachers hope to develop research workers, and high-grade specialists, but these phases of practice are highly individualistic, and the great majority of students will fill places in the larger field of general dentistry. The study we are making is an attempt to disassociate the personality of the successful dentist in general practice. We will consider him as an integrate personality, possessing all of the traits or qualities of personality that are essential to success in his field, and by a process of analysis or dissection, by members of his profession best qualified to judge, we shall try to ascertain these essential traits and their relative value, in order that other members of our profession, if possible, may be benefited by our findings.

Webster defines "success" as "obtaining the object desired." The Standard Dictionary defines "successful" as "the accomplishment of what is attempted or attended, to obtain the object or end desired." The object of dental art and science, according to Herman Prinz, is "to reduce suffering, to cure disease, and what is most important of

1 Read at a session of the Ninth General Meeting of the International Association for Dental Research: Journal of Dental Research, 1931, xi, p. 495; June. 
all, to maintain health by dental prophylaxis." A successful dentist should be one who accomplishes this end or objective. A great many of our fellow practitioners, at first thought, would object to this statement of dental success, but $I$ think close analysis will convince them that by acomplishing this end "all else will be added unto them." My conception of a successful dental practitioner agrees with that of Dr. Prinz, and our investigation is an attempt to compile a list of personality traits, which, if possessed by an individual with normal motivation and training, would predispose for his success. It is important that we define first, a trait, then a personality trait. A trait is a distinguishing feature or quality, especially of mind or character, or anything produced by them. A trait of personality or an emotional complex is a tendency to react with a particular emotion to situations of a certain class, and under the influence of the emotion to exhibit certain types of thinking and conduct. It is generally a mode of reaction that tends to differentiate one individual from another. The study we are making is of these personality traits and a method of selecting them from the personalities of successful dental practitioners.

The simplest method of trait selection is the compilation by an individual of a list of a certain number of traits. The possessor of these traits will secure the desired object or end, success. Franklin selected thirteen moral virtues and carefully followed their precepts in an effort to lead the good life of the philosopher. A second method is to secure a consensus of opinion as to a trait selection, such as was formulated in the Oath of Hippocrates and in other professional or vocational codes. A third method, that of personnel analysis-the one we adopted-is the most exact. In this method significant qualities, traits, or ideals of both the successful and unsuccessful members of a specified group are analyzed, and the desirable traits are placed on a list. Undesirable traits, noted as a cause of failure, are changed to their opposites and placed on the list. Competent judges in the dental profession might be selected from

(1) Dentists employing other dentists

(2) Members of dental faculties

(3) Patients of dentists

(4) Dentists themselves

(5) Individuals having intimate contacts with the dentist in private, 
social, or commercial life. Dental-supply dealers could be utilized to a limited extent.

Charters, in his "Teaching of Ideals," says a personnel of thirty judges is sufficient for a comprehensive study of trait selection. Our investigation is in its preliminary stages, but as our first step we have selected judges from the dental faculties of schools scattered over the United States. Charters states that most professions or vocations present a list of fifty traits at the beginning of a study, but this makes too fine a distinction or line of demarcation among the traits, and a final list should contain not more than twenty. After traits are selected, they must be described either in synonymous terms or in trait actions. A trait action is an activation performed by a person that demonstrates the possession of a trait. We might describe the trait action of ambition as follows:

(1) The studying of current professional literature

(2) Keeping well informed on topics of the day, current events, etc.

(3) Taking graduate or extension courses at intervals in order to keep abreast of professional progress

(4) Developing the cultural side of life, being interested in art, music, literature, etc.

The value of a trait in a list is based upon the number of times it is mentioned by the men who were interviewed or solicited in making the study. The measuring of more than a few traits of personality is difficult, and at present speed and accuracy are the only traits that can be measured fairly accurately. To accomplish the greatest accuracy in evaluating or measuring selected traits, we must

(1) Determine carefully what traits should be measured.

(2) Study the different degrees of complexity of each trait. For instance, honesty is a valuable trait, but the degree to which an individual possesses this trait is hard to determine. Honesty in the dental profession is easier to evaluate than honesty in industry, for the dental profession has a narrower range and hence should be easier to scale.

(3) Remember that subjective opinion plays a large part in measuring traits (two or more judges examining the same trait in an individual will give varying estimates of the amount that this trait is possessed by the individual). It is not uncommon to find an indi- 
vidual graded $A$ in friendliness by one judge, $B$ by three, and $D$ by a fifth.

(4) Give a more exact definition of what is meant by the terms used to describe traits. Initiative to one person may imply force, drive, or persistence; to another it may mean ability to begin or institute, even though the act is not carried to completion.

In spite of the obstacles listed above, we are encouraged to carry on our study by Thorndike's statement: "Whatever exists at all exists in some amount, and anything that exists in amount can be measured."

SUMMARY A

Original list of fifty traits of personality as compiled by Professor J. F. Dashiell
1. Robust physique
20. Religiousness
2. Energy (live-wire type)
21. Self-interest
22. Impressiveness of ap-
36. Ability to make a quick
3. Good memory
4. Tactfulness pearance
5. Good personal ap- 23. Sympathy pearance
24. Open-mindedness decision
37. Reflectiveness
38. Impulsiveness
39. Thrift
6. Initiative
25. Precision
7. Patience
8. Industry
9. Resourcefulness
10. Accuracy
11. Readiness of speech
26. Cautiousness
40. Masterfulness
41. Stable-mindedness
27. Neatness and orderli-
42. Punctuality
43. Boldness
44. Firmness
28. Ability to be "a good mixer"
45. Analytical-mindedness
46. Originality
29. Refinement
47. Speculativeness
30. Adaptability
48. Independence
13. Self-control
14. Matter-of-factness
31. Suggestibility
49. Conservatism
15. Aggressiveness
16. Optimism
17. Honesty
18. Leadership
32. Emotional stability
33. Investigativeness
34. Possession of good habits
19. Courage
35. Self-assurance
50. Economy

We have selected a list of fifty traits as compiled by Prof. J. F. Dashiell of the Psychology Department of the University of North Carolina (Summary $A$ ). This list was compiled from authoritative sources, such as articles and books that dealt with psychological aspects of vocational guidance. The list was sent to one hundred dental teachers scattered over this country, and seventy-nine of the lists were returned to us. The recipients of this list were asked to select twenty traits and number them, in the order of the importance of their possession, from one to twenty, one being the most important and twenty the 
least important. The lists were returned to me and compilations made as to the number of votes each trait received, and as to the ranking of every trait that received a vote or votes in the 1-20 scale (Summary B). Our present report is but a preliminary one. We shall make a second check on the twenty-odd traits selected in this

\section{Sumary B}

The twenty-two most important traits selected by seventy-nine dental teachers throughout the United States, and their ranking compiled by three different statistical methods, with a final or order-of-merit listing of these selected traits

\begin{tabular}{|c|c|c|c|c|c|}
\hline \multirow{2}{*}{$\begin{array}{l}\text { TRATT } \\
\text { NUMBBER* }\end{array}$} & \multirow{2}{*}{ NAME } & L.F. & M.W. & PER CENT & Av. \\
\hline & & 1 & 2 & 3 & RK \\
\hline 17 & Honesty & 1 & 1 & 1 & 1 \\
\hline 10 & Accuracy & 2 & 6 & 9 & 5.6 \\
\hline 4 & Tactfulness & 3 & 5 & 3 & 3.6 \\
\hline 8 & Industry & 4 & 2 & 8 & 4.6 \\
\hline 5 & Good personal appearance & 5 & 4 & 13 & 7.3 \\
\hline 34 & Possession of good habits & 6 & 8 & 5 & 6.3 \\
\hline 23 & Sympathy & 7 & 10 & 4 & 7.0 \\
\hline 13 & Self control & 8 & 9 & 11 & 9.3 \\
\hline 29 & Refinement & 9 & 13 & 6 & 9.3 \\
\hline 12 & Keen observation & 10 & 11 & 12 & 11.0 \\
\hline 6 & Initiative & 11 & 7 & 14 & 10.6 \\
\hline 7 & Patience & 12 & 12 & 7 & 10.3 \\
\hline 42 & Punctuality & 13 & 15 & 10 & 12.6 \\
\hline 9 & Resourcefulness & 14 & 14 & 15 & 14.3 \\
\hline 25 & Precision & 15 & 16 & 20 & 17.0 \\
\hline 1 & Robust physique & 16 & 17 & 19 & 17.3 \\
\hline 3 & Good memory & 17 & 18 & 18 & 17.6 \\
\hline 24 & Open-mindedness & 18 & $\mathbf{x}$ & 16 & 17.0 \\
\hline 45 & Analytical-mindedness & 19 & $x$ & 17 & 18.0 \\
\hline 19 & Courage & 20 & 19 & $\mathrm{x}$ & 19.5 \\
\hline 27 & Neatness and orderliness & $\mathrm{x}$ & 3 & 2 & 2.5 \\
\hline 35 & Self assurance & $\mathrm{x}$ & 20 & $\mathrm{x}$ & 20.0 \\
\hline
\end{tabular}

* In Summary $A$.

first study. A list of these traits will be sent to one hundred dentists who have been successful in their practices. The traits selected in our final analysis will have their respective trait actions carefully described, using synonymous terms so that the subjective element will be replaced by the objective element in judging an individual as to 
the amount of any given trait he possesses. The final product should represent a fairly accurate means of measuring a dentist's personality based on a hypothetical personality set up by fellow dentists.

The importance of using psychological tests in the various professions is becoming more apparent. The Minnesota Tests for Mechanical Aptitude may have an important bearing on the study of dental students in their freshman year. Mechanical aptitude is important in our work, and the utilization of these tests, as an adjunct to our technical instruction, may be of great value. The time has come when each teacher must study his students as individuals, and not en masse. Department heads in our dental schools should have a personality profile of each student under his supervision, which is a composite of the opinions of the members of his staff, for his judgment alone is too likely to err in many cases. The careful use of personality rating-scales would give the department head and each member of his staff a "blue print" of each student as determined by a group judgment.

The extent of one person's inconsistencies in trait action compared to those of other persons, in regard to certain actions, responses, and situations, marks the degree of dissociation of our personalities. In other words, it denotes how far we are from the desirable integrate or normally successful personality. The individual who possesses this integration has sureness and effectiveness, and puts behind his actions his full drive and force. Integration is not given, it is achieved. The aid and help we as teachers can give our undergraduates, to develop a successful personality or full integration, will be a satisfaction to us, for our success is interdependent upon the success of our students. We, too, will then have attained the end or object desired, success.

\section{REFERENCES TO LITERATURE}

BRown, R. K. 1930 Research in the use of a rating scale as a means of evaluating the personalities of senior dental students. Journal of Dental Research, $\mathrm{x}, \mathrm{pp}$. 271, 372; June.

Charters, W. W. 1928 Teaching of ideals, pp. 24 to 64. Macmillan Co., New York.

DAshiel, J. F. 1930 Personality traits and the different professions. Journal of Applied Psychology, xiv, p. 197; June.

EdTTORIaL. 1930 Is dentistry a success? Dental Roster, iv, p. 25; December 20.

Patterson, D. G., Elliotr, R. M., Anderson, L. D., Toops, H. A., ANd Heidbreder, E. 1930 Minnesota mechanical ability tests, p. 3-22. University of Minnesota Press, Minneapolis, Minn.

RoBack, A. A. 1928 Psychology of character, p. 354. Harcourt Brace. 